\title{
Methanol Electro-Oxidation on Bimetallic PtMo/C Catalysts and Pt/C - Mo/C Mechanical Mixtures
}

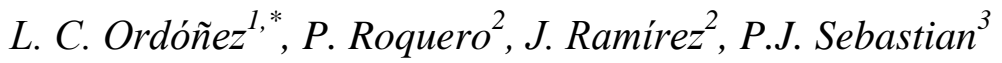 \\ ${ }^{1}$ Unidad de Energía Renovable-CICY, C. 43 No 130 Col. Chuburná de Hidalgo, Mérida Yucatán, \\ México. CP 97200. \\ ${ }^{2}$ Facultad de Química, Universidad Nacional Autónoma de México, Cd. Universitaria, México D. F. \\ 04510, México. \\ ${ }^{3}$ Instituto de Energías Renovables, Universidad Nacional Autónoma de México, Temixco, Morelos, \\ México. CP 62580. \\ *E-mail: $\underline{\text { lcol@ cicy.mx }}$
}

doi: $10.20964 / 2016.07 .76$

Received: 9 July 2015 / Accepted: 7 February 2016 / Published: 4 June 2016

The role of molybdenum in carbon-supported Pt-Mo electrocatalysts was studied with the aim of obtaining active materials to be used as anodes in the methanol electro-oxidation reaction. The catalysts were synthesized by the thermolysis of Mo and Pt carbonyls. Two series were obtained: bimetallic $\mathrm{PtMo} / \mathrm{C}$, and $\mathrm{Pt} / \mathrm{C}$ plus $\mathrm{Mo} / \mathrm{C}$ mechanical mixtures. The Mo content was changed, with the atomic ratio ranging from 0.0 to 1.0. XRD and XPS analyses of the fresh materials indicated the presence of $\mathrm{Pt}^{0}$ and molybdenum oxides $\left(\mathrm{MoO}_{\mathrm{x}}\right)$. XRD of $\mathrm{Mo} / \mathrm{C}$ treated electrochemically at constant potential in $\mathrm{H}_{2} \mathrm{SO}_{4}$ confirmed the formation of molybdenum bronzes with different protonation degrees $\left(\mathrm{H}_{\mathrm{x}} \mathrm{MoO}_{3} 0.3<\mathrm{x}<2\right)$. Cyclic voltammetry indicated that $\mathrm{Mo} / \mathrm{C}$ does not present the capacity to oxidize methanol nor the intermediate species, but it did show promoter behavior. In the PtMo/C series, low molybdenum contents present the maximum promoting effect on methanol electrooxidation, as evidenced by lower onset potentials for the methanol oxidation reaction with respect to the Pt/C catalyst. Similar results were registered by the mechanical mixtures, where the Pt sites are separated from the molybdenum bronzes, suggesting that Pt poisoned sites, caused by methanol electro-adsorption, are cleaned by the interaction with molybdenum bronzes $\left(\mathrm{H}_{\mathrm{x}} \mathrm{MoO}_{3}\right)$ through a process of surface diffusion of oxygen-containing species.

Keywords: PtMo/C, mechanical mixtures, Pt/C, Mo/C, DMFC, methanol electro-oxidation, electrocatayst. 


\section{FULL TEXT}

(C) 2016 The Authors. Published by ESG (www.electrochemsci.org). This article is an open access article distributed under the terms and conditions of the Creative Commons Attribution license (http://creativecommons.org/licenses/by/4.0/). 